\title{
An Investigation into the Change in the Metage Currency System in Southern Taiwan during the Early Japanese Rule Period: 1897-1900
}

\author{
Yenhao Huang \\ National Chengchi University \\ Email: broadinterior12@gmail.com
}

How to cite this paper: Huang, Y. (2021). An Investigation into the Change in the Metage Currency System in Southern Taiwan during the Early Japanese Rule Period: 1897-1900. Open Journal of Social Sciences, 9, 26-38.

https://doi.org/10.4236/jss.2021.94003

Received: December 17, 2020

Accepted: April 3, 2021

Published: April 6, 2021

Copyright $\odot 2021$ by author(s) and Scientific Research Publishing Inc. This work is licensed under the Creative Commons Attribution International License (CC BY 4.0).

http://creativecommons.org/licenses/by/4.0/

(c) (i) Open Access

\begin{abstract}
This study aims to discuss about the change in the metage currency system during the early Japanese rule period, with southern Taiwan as an example. The metage currency system used in Taiwan in the late Qing rule period one yuan is weighed seven mace and two candareens in northern Taiwan, seven mace in central Taiwan, and six mace and eight candareens in southern Taiwan. In the early Japanese rule period, the metage currency system primarily underwent a change in southern Taiwan, increasing the denomination of one yuan from six mace and eight candareens to seven mace and three candareens. To date, there have been few studies on this drastic change. We therefore aimed to expand on this subject. By reviewing the financial records in southern Taiwan between 1897 and 1900, we conclude that the custom of weighing money would have continued to be practiced in regions where the supplementary silver currencies in circulation had a greater ease-of-use; while in regions where only the paper currency had a greater ease-of-use, the custom of weighing money would fall out of practice and the silver standard adopted would switch to one based on the silver content of the silver coin that could be redeemed with paper currency.
\end{abstract}

\section{Keywords}

Metage Currency System, Sliver Standards, Currency in Circulation, Taiwan under Japanese-Rule Period

\section{Introduction}

Metage currency system has been regarded as an important issue of Taiwan's economic history. It dominated the circulation of silver currency as silver currencies were major mediums of exchange in Taiwan until the early $20^{\text {th }}$ century. 
Since the opening of Taiwanese ports in the Qing dynasty, Taiwan had continued to prosper in the development of maritime trade and merchant organizations. With different countries involved in the trading activities in Taiwan, the phenomenon of "merchants from different countries trading with different silver currencies" was commonplace (Lian, 1920). Therefore, one is able to conclude that there was a complicated assortment of different currencies in circulation at the time. ${ }^{1}$ It should first be noted that the monetary unit for silver coins was yuan (yen). As each silver coin differed in quality and weight, it would be impractical to forcibly assign each coin with the same value in yuan. Thus, in order to use them in trading, a method to assess the value of silver coins that was accepted by both parties must be established before the silver coins may be granted the function of a medium of exchange.

Furthermore, different silver coins also varied in silver content, not to mention counterfeit silver coins with low silver content those were circulating in the economy. To validate the authenticity of silver coins, merchants often left chop marks, which caused their depreciation in weight. As many merchants were concerned with counterfeit coins, different chop marks may be left on silver coins as they passed through different merchants. Over time, these silver coins are covered in multiple chop marks made by different merchants and gradually depreciate in weight. In this way, the depreciation in weight caused by this anti-counterfeiting measure created further differences amongst these silver coins that were already inconsistent in specifications. As a result, these chop marked coins could no longer be considered as having the same value and were referred to as "chopped dollars". In other words, although the chop marks validated the quality of such silver coins, they could no longer be traded using their face value, but were rather assessed of their value by weight. For this reason, the nominal currency system, which designated the silver coins' face value of one yuan, could not function and was replaced by the metage currency system that assessed the value of silver coins by weight.

The prevalence of the metage currency system is therefore caused by the difference between intrinsic and nominal values among many silver currencies and chopped dollars. Used in trading transactions to assess the value of silver coins so that both parties can agree on the value of the silver coins used, the metage currency system was born in response to the uniqueness and complexity of the silver coins and out of the needs for smooth transactions.

In the late Qing rule period, silver currencies could be found circulating in Taiwan after being weighed in tael and mace and converted to the denomination of yuan (Li \& Huang, 1976). ${ }^{2}$ Based on the historical records on the metage cur-

\footnotetext{
${ }^{1}$ The currencies used in Taiwan during the Qing dynasty can be generally classified into two categories: silver currencies and copper currencies. Most silver coins were minted by foreign countries but are different in composition and weight. Therefore, although they are collectively called 'silver coins,' it is actually a general term for the complicated assortments of different silver currencies (Kitayama, 1935).

${ }^{2}$ Additionally, according to the observation made by Cheng (2001) from his review of historical contracts, the 1750s saw the return of silver coins as the dominant circulating currencies in the Taiwanese market.
} 
rency system in the late Qing rule period compiled in 1904, it can be pointed out that the denomination of yuan used in Taiwan differed slightly between different regions of the island. One yuan was seven mace and three candareens of treasury standard silver (later referred to as the seventy-two-candareens silver standard) in northern Taiwan, seven mace (seven-mace silver standard) in central Taiwan, and six mace and eight candareens (sixty-eight-candareens silver standard) in southern Taiwan (Office of Finance, Department of Civil Affairs, GovernmentGeneral of Taiwan, 1904). From these records, we can see the regional difference in conversion rates of the metage currency systems and identify it as one of the major features of the system in Taiwan during the late Qing rule period and the early Japanese rule period that followed.

In the hope of determining the chronological and geographical features of and changes to the silver standards in Taiwan over time, we focused on this issue and compared records on the metage currency system used in Taiwan in the late Qing rule period and in the early Japanese rule period as compiled in two books, The Currency System of Taiwan (Office of Finance, Department of Civil Affairs, Government-General of Taiwan, 1904) and A Brief Introduction to the Land Usage in Taiwan (Temporary Taiwan Land Investigation Bureau, 1905), respectively. We has illustrated below in Figure 1 the geographical distribution of the different silver standards used in the metage currency system based on the descriptions in the two books.

It can be seen in Figure 1 that the metage currency system's silver standards used in different parts of Taiwan between the end of the $19^{\text {th }}$ century and the beginning of the $20^{\text {th }}$ century and that they were different in both their exterior appearance and intrinsic characteristics. The topics relevant to this paper can be generally described in the two following points.

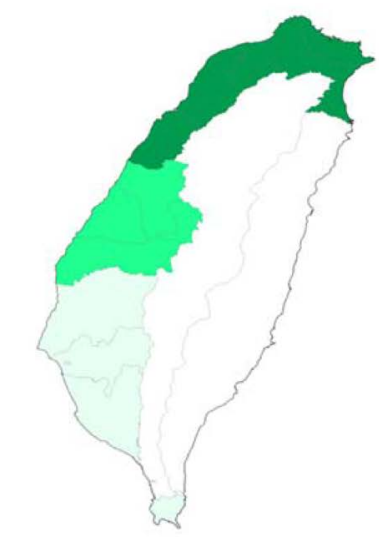

Late Qing rule period

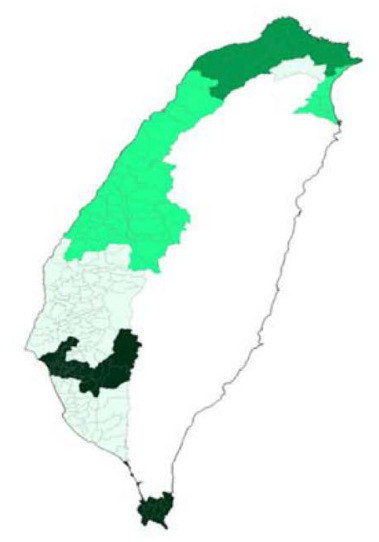

Early Japanese rule period
The fixed weight of a one-yuan coin

7 mace and 3 candareens

7 mace and 2 candareens

7 mace

6 mace and 8 candareens N/A

Data source: The illustration pictured left is based on the Taiwan Sotokufu Archives, Collection No. 00009714035 and Office of Finance, Department of Civil Affairs, Government-General of Taiwan (1904). The illustration pictured right is based on Temporary Taiwan Land Investigation Bureau (1905).

Figure 1. The silver standards used in the metage currency system of Taiwan during the late Qing rule and early Japanese rule periods. 
First, the metage currency system's silver standards vary among different geographical regions. Leaving aside the fact that the investigations were conducted separately in time, the data clearly shows the difference among the silver standards used in different parts of the island. This phenomenon had arisen from the various characteristics of the trading activities in Taiwan. Considering the historical context, the reason may be the lack of a unified trading circle. Instead, the island's separate trading circles in the northern and southern regions were independently connected with Hong Kong and Macau, forming geographically isolated economic circles that gave the currencies circulating in Taiwan their geographically isolated feature (Kobayashi, 1977). Furthermore, geographical barriers also prevented a unified market across the island from forming, thus negating the need to unify the currencies in circulation ( $\mathrm{Wu}, 2005)$. From these facts, we may deduce that the difference among the silver standards used in different parts of Taiwan stemmed from the isolation of the trading circles on the island. In other words, the geographical difference among the silver standards seems to reflect the infrequent trading activities and interactions between different regions of Taiwan.

Second, the silver standards differ over time. By comparing the illustration pictured left in Figure 1-which shows the geographical distribution of the silver standards in Taiwan during the late Qing rule period-and the illustration pictured right in Figure 1-which shows their distribution in Taiwan during the early Japanese rule period-we can see the changes to the silver standards between the two time periods. In general, the seventy-two-candareens silver standard was used in northern Taiwan and the seven-mace silver standard was used in central Taiwan; as for southern Taiwan, the sixty-eight-candareens silver standard originally used during the late Qing rule period was later replaced by the seventy-three-candareens silver standard in the areas around Tainan City and in Hengchun.

This highlighted a phenomenon worth investigating, which is that the silver standards not only varied among different geographical regions but also differed over time. And also, the monetary system is always a fundamental topic in the study of economics, and the metage monetary system is a noteworthy part of Taiwan's economic history. As Figure 1 depicts the conversion rates of the metage currency systems could change over both time and region, but there have been few studies on these two drastic changes. Hence these changes in the silver standards in southern Taiwan as seen in the comparison between the late Qing rule and early Japanese rule periods is our major topics of discussion in this paper.

This paper is structured as follows: the first section is the introduction, which gives a brief description of the topics explored in this paper; the second section is a description of the metage currency system through literature review; the third section uses the investigation results on the currencies in circulation during the early Japanese rule period to explain the changes to the silver standards and the use of silver currencies; the last section is the conclusion. 


\section{Kitayama's (1935) Explanation of the Metage Currency System and Silver Standards}

Fukujiro Kitayama (1901-1984) can be seen as a pioneer in the studies of the monetary history of Taiwan, especially those focused on investigating the phenomenon undergone by the currencies circulating in Taiwan between the late Qing rule and early Japanese rule periods. His works titled The Metage Currency System in Taiwan and the Japanese Monetary Policy was published in 1935 and is considered important literature on the related topics. ${ }^{3}$ We therefore used $\mathrm{Ki}$ tayama's explanation of yuan in the metage currency system as the starting point, which is quoted as follows:

“The term 'yuan' (yen) had always referred to 'one piece of foreign silver coin', but the value (silver content) of one 'yuan' have not always been the same as other coins of the same denomination. This is why specific silver coins were chosen for certain reasons to serve as the 'standard' in silver content. In practical use, these 'standard silver coins' were used to mark the prices of regular commodities or set debt amounts in agreements; they also became the standard unit used to assess the value (silver content) of other silver coins." (Kitayama, 1935)

Kitayama (1935) believed the so-called standard for the metage currency system was the silver content of these "standard silver coins" that held a dominant position as the "one yuan" used to assess the value of other silver coins. Thus, different silver coins may be converted to a single monetary unit. It is worthy to note that Kitayama believed that silver currencies that served as the standard denomination should be based on the silver content of either of the following types of currencies.

1) Silver coins with the largest amount in circulation;

2) Silver coins specifically accepted for taxes.

However, Kitayama (1935) further suggested two perspectives of looking at the change in the metage currency system in southern Taiwan, which is the focus of this paper. From these perspectives, we can catch a glimpse of the currency system used at the time by examining the circulation of silver coins with the largest amount in circulation or silver coins accepted for taxes.

As described in the previous section, the change of the silver standard in southern Taiwan to the seventy-three-candareens silver standard that occurred during the early Japanese rule period was limited to the areas around Tainan City and in Hengchun. According to Kitayama's theory, there should be, at the time, a type of silver coin that weighed seven mace and three candareens, had the largest amount in circulation, and was specifically accepted for taxes. Among

\footnotetext{
${ }^{3}$ As Chou (1980) mentioned that "In the study of the monetary history of Taiwan, information concerning currencies is the most lacking. Among the literature on this topic, none is more authoritative than Fukujiro Kitayama's work published in 1935." One of Kitayama's most important works is to explain the metage currency system. As seen from the quote above, the importance of the relevant discussions in this literary work to future studies is self-evident.
} 
the currencies circulated in Tainan and Hengchun at the time, the Japanese yen silver coin weighed seven mace and three candareens (Temporary Taiwan Land Investigation Bureau, 1905). We therefore examined Japanese yen silver coins that weighed seven mace and three candareens to determine if they meet the criteria stated by Kitayama for a "standard silver coin" that would hold a dominant position.

The reasoning behind the first criterion seems quite intuitive. Generally speaking, when a silver currency became the majority circulating in the market, merchants would use it as the "standard silver coin" used to valuate items so as to simplify the calculation and trading process. However, we found that the statistical records on the number of silver currencies in circulation in different regions of Taiwan during the late Qing rule period and the early Japanese rule period that followed are extremely lacking. Among the available data, the records on the area around Tainan City are relatively complete and representative. We therefore examined the amount and percentage of currencies circulating in Tainan City at the time as described below.

According to historical records, the amount of currencies in circulation in Tainan City around 1901 roughly totaled over 200,000 yen, with the percentage of different currencies as follows: Taiwanese yen banknotes and Japanese yen silver coins accounted for $40 \%$, Mexican peso silver coins accounted for $20 \%$, counter stamped Japanese yen silver coin accounted for 20\%, the remaining $20 \%$ consisted of chopped dollars (Kawakita, 1902). From these data, we can conclude that Japanese silver currencies accounted for a relative majority of $60 \%$ of the currencies in circulation in Tainan City at the time. Under this circumstance, the silver coin with the largest amount in circulation-the Japanese yen silver coin-was naturally used when converting other silver currencies or chopped dollars to the monetary unit of "yen". Therefore, from the amount and percentage of the silver currencies circulating in Tainan City at the time, Kitayama's argument that the silver currency with the largest amount in circulation held the dominant position as the "standard silver coin" is valid as the Japanese yen silver coin that weighed seven mace and three candareens was indeed the "standard silver coin" that held a dominant position based on the circulated amount.

Before discussing the second criterion given by Kitayama-a silver currency accepted for taxes becomes the "standard silver coin"-we believes it necessary to briefly explain the Japanese government's official stance on the foreign currencies circulating in Taiwan at the time and the rules on their acceptance for taxes. Prior to 1897, the Government-General had reluctantly accepted foreign coins and chopped dollars for taxes. ${ }^{4}$ However, with the promulgation of Decree No. 374 in 1897, the Government-General stipulated that "counter stamped one-yuan silver coins" be accepted for taxes at their current value and that foreign currencies and countermarked currencies shall no longer be accepted for

${ }^{4}$ The Japanese government never accepted existing currencies in Taiwan as legal tenders, but was forced to reluctantly accept chopped dollars for taxes during the early rule period (Bank of Taiwan, 1919). 
taxes in the future (Bank of Taiwan, 1919). ${ }^{5}$

However, we think that the correlation between currencies accepted for taxes and the metage currency system as proposed by Kitayama (1935) requires further substantiation. Basically, the Government-General of Taiwan only put restrictions on the types of currencies accepted for taxes but did not explicitly prohibit the use of certain currencies nor call for the public to cease the use of the metage currency system at the start of the Japanese rule period. Therefore, in the following section, we will focus on the investigation results on the currencies circulating in southern Taiwan at the time, beginning with a brief description followed by a discussion of the possible reasons behind the change in the metage currency system, so as to clarify the mechanism through which the movement of currencies affected the metage currency system in Taiwan.

\section{The Currency Usage and the Metage Currency System in Southern Taiwan}

Generally speaking, the reason for the different silver standards in different regions should be linked to the types of currencies in circulation and their usage. The observations made in this paper are therefore based on the Situation Reports on the Local Usage of Coins and Paper Currencies - which were compiled by the local administrative units in 1897 on the currency usage in southern Taiwan and the investigation on currency usage in 1900 compiled in the book Report on the Financial Situation in Taiwan. ${ }^{7}$ Through these investigations conducted in two different time periods, we were able to compare the currency usage in different regions over time and infer the reasons behind the forming of

\footnotetext{
${ }^{5}$ However, several issues arose after the decree's promulgation. The ones that were most discussed in literature include the opportunistic behaviors caused by the fixed rate set by the government and the late tax payment caused by the insufficient amount of "counter stamped one-yuan silver coins". For the first issue, the government attempted to discourage the opportunistic behaviors by adopting a more flexible rate that reflected the market rate (Bank of Taiwan, 1919; Office of Finance, Department of Civil Affairs, Government-General of Taiwan, 1904). As for the second issue, the government relaxed the restrictions on the types of currencies accepted for taxes, allowing taxpayers to use "non-counter stamped one-yuan silver coins" and "Taiwanese yen banknotes" to pay taxes (Kitayama, 1935). Although the Government-General relaxed on the types of currencies accepted for taxes, they were still limited to Japanese yen silver coins and the Taiwanese yen banknotes used to redeem said silver coins. It can therefore be concluded that the Japanese yen silver coin was the "standard silver coin" used in taxation that held a dominant position.

${ }^{6}$ For how the Department of Civil Affairs, Government-General of Taiwan requested the Situation Reports on the Local Usage of Coins and Paper Currencies and how they were compiled, see the Currency Circulation Situation and Relations Documents (Originally Tainan County) taken from the Taiwan Sotokufu Archives, Collection No. 00009785013. It is worthy to note that according to the official document No. 722, the investigation had to be conducted in accordance with the stipulated format and the investigators were advised to "prioritize accuracy in the investigation of currency circulation and record the actual situations observed in the local hongs, merchant houses, pawn shops, and other shops where the transaction of currencies takes place, with a minimum of three or four locations. If great discrepancies are found among the investigated shops, individual investigation records shall be submitted." The attention given to these investigations can thus be seen. ${ }^{7}$ The currency circulation situation of southern Taiwan in 1900 was compiled by Kawakita (1902). Since the format is almost identical to that stipulated in the official document No. 722 mentioned in the preceding footnote, one can see the continuation between the two investigations conducted in two different time periods.
} 
the standard silver coin.

It should first be noted that in order to discuss the impact of silver coins on the existing currency system in Taiwan, one should first look at the circulation of silver coins or banknotes. ${ }^{8}$ We therefore focused on the various silver coins circulating in Taiwan and the Taiwanese yen banknotes, the circulation situations of which are compiled in Table 1.

Among the results obtained in the currency investigations conducted in 1897, those of Tainan, Chiayi, and Donggang were more complete ones than other regions. We therefore examine the results from these three regions. It should be noted that Tainan is situated in the center of southern Taiwan, while Chiayi and Donggang lie to its north and south, respectively. Due to the geographical relations between the three regions, the conclusion drawn from the examination should be representative of the currency circulation situation in southern Taiwan at the time. Furthermore, in terms of the changes to the silver standards discussed in this paper, we can determine the possible reasons behind the forming of the standard silver coin through the changes, or lack thereof, in the silver standards used in the three regions-with Tainan replacing the sixty-eight-candareens

Table 1. The currency circulation situation in Tainan, Chiayi, and Donggang in 1897 and 1990.

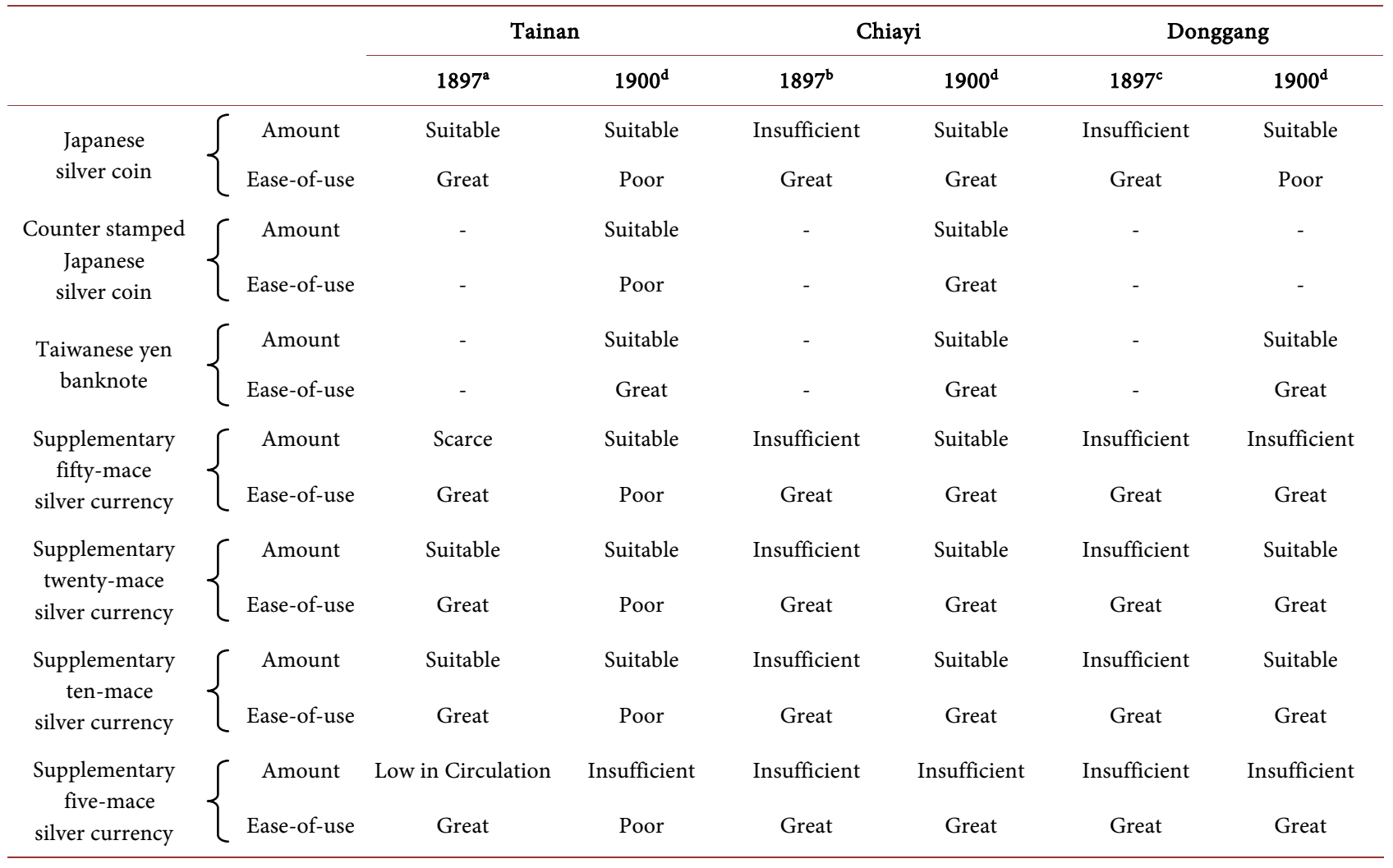

Data source: The data of a is from the Investigation of the Currency Circulation Situation (January to November), Scan No. 000097160550333; the data of b is from the Local Circulation Situation of Coins and Paper Currencies in Chiayi (Originally Tainan County); the data of $c$ is from the Currency Circulation Situation and Relations Documents (Originally Tainan County), Scan No. 000097850130183; the data of d referenced the publication of Kawakita (1902). “-” means no available data.

${ }^{8}$ Although Japan had adopted the gold standard at the time, the circulating currencies in Taiwan still remained on the silver standard (Kitayama, 1935). 
silver standard with the seventy-three-candareens silver standard and Chiayi and Donggang maintaining the use of the sixty-eight-candareens silver standard.

It can be observed in Table 1 that the investigations on the currencies in circulation at the time mainly focused on two aspects: whether or not the circulated amount was suitable and whether or not the currencies were easy to use. Firstly, the investigation results show that there was a suitable amount of Japanese silver coins circulating in Tainan in 1897 but an insufficient amount circulating in Chiayi and Donggang; by 1900, there was a suitable amount of Japanese silver coins circulating in all three regions. Secondly, the ease-of-use of Japanese silver coins was great in all three regions in 1897; by 1900, the currency's ease-of-use was only maintained in Chiayi and showed a decline in the two other regions.

It is worthy to note that according to the observations made above, there is no definite correlation between currencies' circulated amount and ease-of-use. That is to say, even if there is a suitable amount of a currency in circulation in a certain region, it does not mean that it would have a great ease-of-use. Vice versa, a currency with great ease-of-use would not necessarily have a suitable amount in circulation.

As for counter stamped Japanese silver coin, there are no records of investigations conducted on this currency in 1897. Originally created for taxes and government expenditures, the counter stamped one-yen silver coins were Japanese silver coins stamped with a mark as per Decree No. 374, which was promulgated in October 1897. This is why no investigations were conducted on counter stamped one-yen silver coins in 1897. However, the records show that by 1900, the counter stamped Japanese silver coin were similar to the Japanese silver coins in their amount and ease-of-use in both Tainan and Chiayi. This phenomenon seems to hint at the use of the metage currency system at the time. Although the counter stamped Japanese silver coin each bore a mark, they are almost equal in weight compared to the Japanese silver coins, leading to the two currencies' similarity in their circulated amount and ease-of-use.

For Taiwanese yen banknotes, there are no records of investigations conducted on this currency in 1897. This is due to the fact that this currency was first issued in 1899 soon after the establishment of the Bank of Taiwan, which is why there are only records of investigations conducted on this currency in 1900. The records of the investigations conducted in 1900 show that the Taiwanese yen banknote was a currency with a suitable amount in circulation and a great ease-of-use in all three regions. Although as paper money, Taiwanese yen banknotes were equivalent to the Japanese silver coins in value, there were still differences between the two currencies in their use in different regions. In Tainan and Donggang, the Japanese silver coin had a poor ease-of-use and the Taiwanese yen banknote had a great ease-of-use; while in Chiayi, both currencies had a great ease-of-use. An interesting observation can be made on the difference in the ease-of-use between the two currencies despite their identical value and suitable amount in circulation. The reason for this phenomenon is due to the 
fact that when presented with different currencies of the same value, people preferred using banknotes that were easy to carry around.

Furthermore, although the Taiwanese yen banknote was equivalent to the Japanese silver coin, it had a greater ease-of-use compared to the Japanese silver coin. This, coupled with the fact that it was pointless to weigh a paper currency, means that the existing custom of weighing money could not be applied to determine the value of paper currencies in the actual transaction of money and goods. It can therefore be concluded that the Taiwanese yen banknote's great ease-of-use in Tainan in 1900 likely played an indirect role in the adoption of the nominal currency system and gradually replaced the metage currency system stemming from the Taiwanese people's preference for silver.

Additionally, according to the results of the investigations conducted on the supplementary silver currencies, these currencies all had a great ease-of-use in Tainan, Chiayi, and Donggang in 1897; however, by 1900, varying degree of changes in their ease-of-use can be observed in different regions: the supplementary silver currencies still had a great ease-of-use in Chiayi and Donggang but have a poor ease-of-use in Tainan. If we look at the ease-of-use of different currencies in Tainan in 1900, all of the currencies except for the Taiwanese yen banknote had a poor ease-of-use.

In terms of their monetary characteristics, the supplementary silver currencies are silver currencies used in case of transactions that require money below the denomination of one yen. This is similar to chopped dollars and their characteristics as metallic currencies due to the following reasons. Firstly, chopped dollars are silver currencies that were damaged to the point of being illegible and are weighed and traded as a silver commodity. The supplementary silver currencies are similar in this regard as they were also traded as a silver commodity. ${ }^{9}$ Secondly, in terms of their usage as currencies, chopped dollars were also used in case of transactions that require money below the denomination of one yen (Kawakita, 1902), thus playing a similar role as the supplementary silver currencies, which served as payment for small transactions. We can therefore see that the two types of currencies were extremely similar, be it in their use as a silver commodity or as media of exchange. ${ }^{10}$

As previously mentioned in the first section, the metage currency system was adopted so that both parties of a transaction could agree on the value of the silver currencies used when consistent silver content could not be achieved among different silver coins or chopped dollars. The circulation of chopped dollars was therefore positively correlated with the use of the metage currency system. A comparison between the currency circulating situations in Tainan in 1897 and

${ }^{9}$ Drastic changes in the silver price during the early Japanese rule period resulted in a large amount of supplementary silver currencies being shipped out of Taiwan as a silver commodity (Kawakita, 1902).

${ }^{10}$ In 1897, the Ministry of the Treasury calculated the amount of chopped dollars in Taiwan using the average amount of supplementary silver currencies held by each person in Japan. The reasoning behind the calculation was also based on the similarity in monetary characteristics between chopped dollars and supplementary silver currencies. Please see Administration Bureau, Ministry of the Treasury (1899). 
1900 shows that the Taiwanese yen banknote had a great ease-of-use while the supplementary silver currencies had a diminishing ease-of-use. Considering the supplementary silver currencies' similarity to chopped dollars, we can infer that chopped dollars would have also trended toward a more stagnant circulation in Tainan and had a poor ease-of-use compared to the Taiwanese yen banknote. Furthermore, the changes to the metage currency system likely resulted from the Taiwanese yen banknote's great ease-of-use, which caused the existing silver currencies in circulation to change to the one-yen denomination of seven mace and three candareens based on the Taiwanese yen banknote and the Japanese silver coin that could be redeemed with said banknote.

On the other hand, the supplementary silver currencies had a great ease-of-use in Chiayi and Donggang from 1897 to 1900, which reflects the wide circulation of chopped dollars in these regions at the time. This is why the existing custom of weighing silver currencies before putting them in circulation was still practiced in Chiayi and Donggang, where the supplementary silver currencies had a great easeof-use and the old sixty-eight-candareens silver standard was still used.

\section{Conclusion}

We conclude that the custom of weighing money would have continued to be practiced in regions where the supplementary silver currencies in circulation had a greater ease-of-use; while in regions where only the paper currency had a greater ease-of-use, the custom of weighing money would fall out of practice and the silver standard adopted would switch to one based on the silver content of the silver coin that could be redeemed with said paper currency. For example, the Taiwanese yen banknote's ease-of-use in Tainan indirectly enhanced the status of its equivalent Japanese yen silver coin to the "standard silver coin" and affected the use of the metage currency system as the seventy-three-candareens silver standard is adopted.

However, it is known that paper money issuance relies on state power in promoting its credibility and gaining public trust, so that the paper money can be widely circulated. During the late Qing rule period, the Qing government was devoid of the concept of monetary sovereignty. As a result, there was a great variety of foreign currency circulating in Taiwan, indirectly leading to the rise of a metage currency system. Subsequently, banknote circulation and silver coin standardization during the early Japanese rule period clearly reflected the influences of state power interference on the usage habits of currency in public. By reflecting on this historical observation, we can provide a reference for the present era.

In terms of currency liquidity, the increase in the paper currency's ease-of-use in Tainan resulted in the changes in preferences toward silver and paper currencies. ${ }^{11}$ This phenomenon indicates that the liquidity of different currencies va-

\footnotetext{
${ }^{11}$ For an economy with multiple currencies in circulation, a currency that can provide a greater value of liquidity services than the other currencies shall have a greater advantage in transactions. For an explanation of the term "value of liquidity services", see Walsh (2010).
} 
ried from different regions and time periods, thus resulting in the differences in people's preferences toward different currencies and changing the silver standards used in the metage currency system. This conclusion also echoes the observation made by Kitayama (1935): "Although the chop marked foreign silver coins could not be completely driven out during the Meiji 30s (1897-1906), nor could the Japanese silver coin completely unify the silver coins in circulation, it is an undeniable fact that the metage currency system was affected in this time period."

Lastly, in terms of data, this article focused on historical documents from Taiwan Sotokufu Archives (Archives of the Government-General of Taiwan) as its core. Despite every possible effort to use primary historical sources for analysis, the historical argument remained flimsy. A closer look at public reactions to the government's monetary policy at that time may provide more detailed evidence. We also consider this as a direction for further research.

\section{Conflicts of Interest}

The authors declare no conflicts of interest regarding the publication of this paper.

\section{References}

Administration Bureau, Ministry of the Treasury (1899). Report of Investigation of Taiwan Economic Matters. Tokyo: Chuaisha.

Bank of Taiwan (1919). Twenty-Year History of the Bank of Taiwan. Tokyo: Bank of Taiwan.

Cheng, W.-C. (2001). The Changing State of Currency Circulation in Early Ch'ing Taiwan. The National Palace Museum Research Quarterly, 19, 227-261.

Chou, H.-W. (1980). Economic History of Taiwan. Taipei: Taiwan Kai-Ming.

Kawakita, K. (1902). Report of Investigation of Taiwan's Financial Matter. In The First Data Book for Financial Matters of Taiwan (pp. 85-283). Tokyo: Bank of Taiwan.

Kitayama, F. (1935). The Metage Currency System in Taiwan and Japan's Monetary Policy. Seigakka Kenkyu Nenpo, 2, 1-283.

Kobayashi, H. (1977). Japan's Occupation Policy on Taiwan II. The Economic Review of Komazawa University, 8, 59-66.

Li, M.-S., \& Tien-Chuan, H. (1976). Study on Taiwan's Monetary System during the Qing-Rule Period. Bulletin of History Department National Cheng Kung University, 3, $1-54$.

Lian, H. (1920). A General History of Taiwan. Taipei: Jong Wen.

Office of Finance, Department of Civil Affairs, Government-General of Taiwan (1904). The Currency System of Taiwan. Taipei: Taiwan Nichinichi Shinpo.

Taiwan Sotokufu Archives. Conversion Rate between the Silver Liang and the Japanese Currency as Replied by the Chief of Finance Hashiguchi. Collection No. 00009785013.

Taiwan Sotokufu Archives. Currency Circulation Situation and Relations Documents (Originally Tainan County). Collection No. 00009714035.

Temporary Taiwan Land Investigation Bureau (1905). A Brief Introduction to the Land Usage in Taiwan (p. 3). Taipei: Taiwan Sotokufu. 
Walsh, C. E. (2010). Monetary Theory and Policy (3rd ed.). Cambridge, MA: MIT Press.

Wu, T.-M. (2005). Taiwan's Consumer Price Index in the Rural Area: 1902-1941. Taiwan Economic Review, 33, 321-355. 